\title{
Invasive Species and Evolution
}

\author{
Alycia L. Stigall
}

Published online: 22 April 2012

(C) Springer Science+Business Media, LLC 2012

\begin{abstract}
Invasive species are a major threat to modern ecosystems and cause billions of dollars in economic damage annually. The long-term impacts of species invasions are difficult to assess on ecological timescales available to biologists, but the fossil record provides analogues that allow investigation of the long-term impacts of species invasions. Two case studies of ancient invasions, the Late Devonian Biodiversity Crisis ( $\sim 375$ million years ago) and the Late Ordovician Richmondian Invasion ( 446 million years ago), provide insight into the effect of invasive species on extinction, speciation, and ecosystem structuring. During both intervals, invasive species are characterized by broad ecological tolerances, broad geographic ranges, and higher-than-average survival potential through the crisis interval. Among the native species, narrowly adapted ecological specialists are more likely to become extinct, while broadly-adapted generalist species persisted through the invasion interval by modifying aspects of their ecological niche through niche evolution. In addition, formation of new species practically stopped during the invasion intervals due to reduced opportunities for geographic isolation and speciation. The results of these impacts produced postinvasion biotas with less diversity, greater biotic homogenization between regions, and a lack of new species forming. Conservation efforts to eradicate invasive species may help mitigate these outcomes in the current biodiversity crisis.
\end{abstract}

Keywords Paleontology · Biogeography - Speciation . Extinction · Introduced species · Marine - Biodiversity . Competition

\footnotetext{
A. L. Stigall $(\bowtie)$

Department of Geological Sciences and OHIO Center for Ecology and Evolutionary Studies, Ohio University, 316 Clippinger Laboratories,

Athens, OH 45701, USA

e-mail: stigall@ohio.edu
}

\section{Introduction}

The introduction of non-native species into modern ecosystems is one the primary contributors to modern biodiversity loss (Enserink 1999). These non-native taxa have been introduced both intentionally (such as songbirds by European immigrants in the 1800s) and accidentally (such as zebra mussel larvae hitching rides in ballast water of ocean liners). Typically, introduced species are referred to as invasive species once they have established populations within the ecosystem that are both self-sustaining and increasing in size (Lockwood et al. 2007; Davis 2009). According to the official U.S. Department of Agriculture definition, introduced species are referred to as invasive species when they are introduced to an ecosystem to which they are not native and their introduction causes environmental harm or harm to human health (http:// www.invasivespeciesinfo.gov/). In the United States alone, invasive species cause environmental losses and damages of over $\$ 120$ billion dollars annually (Pimentel et al. 2005).

Due to their significant impact on modern ecosystems and government budgets, a substantial number of studies have examined the effects of invasive species in modern ecosystems, and aspects of their immediate and short-term ecological impacts are well understood (reviewed in Lockwood et al. 2007). Modern invasive species have been documented to cause ecosystem restructuring, both in terms of simplifying food webs and altering resource utilization patterns. A classic example is the spread of kudzu (Pueraria montana var. lobata), a vine introduced in the late 1800 s for erosion control that now crowds out native species in the United States (Blaustein 2001). This single species overgrows and chokes out the native vegetation, resulting in ecosystem degradation by overgrowth of entire landscapes in the southeastern United States.

The effect of modern invasive species on evolutionary processes of extinction and speciation, however, is less clear 
(Davis 2003). In modern ecosystems, the only documented cases of invaders directly causing extinction involve predator species overutilizing prey items. A prime example is the brown Treesnake (Boiga irregularis) which was inadvertently introduced to Guam probably as a stowaway in ship cargo during the early 1950s (Fritts and Rodda 1998). Due to abnormally abundant prey resources on Guam and the absence of natural predators and other population controls, brown tree snake populations reached unprecedented population numbers (up to 13,000 per square mile) and caused extinction of endemic ground-nesting bird species and extirpation of most of the other vertebrate forest species from the island. A more subtle form of extinction, genetic extinction - in which the unique genome of a native taxon is lost through hybridization with closely related invaders - has also been demonstrated, particularly in fish (Lockwood et al. 2007). Competition between native and invading species may result in local extirpations of native species, but no compelling cases of global extinction resulting from competition with introduced species exist (Lockwood et al. 2007). Impacts of modern invasive species on speciation are difficult to access because the speciation process takes many generations to complete.

The timescale in which biological or ecological experiments can be run precludes classic "invasion biology" from assessing the long-term effects - thousands of years or more —of modern human-mediated introductions. However, species invasions are documented throughout the fossil record, and studying these ancient invasions can help to establish an understanding of the long-term impacts of invasive species on modern biodiversity (Stigall 2010a). Fossil invasions can be identified by mapping species ranges geographically and temporally within an evolutionary context; species that expand their geographic range during their lifetime or in relation to their ancestral species may be considered invasive (Rode and Lieberman 2004). Since not controlled by humans, ancient invasions are facilitated the by the collapse of barriers that normally constrain species ranges. These barriers are varied and include climatic barriers, such as temperature and seasonality, geographic barriers, such as tectonic arches or ecological barriers. Species invasions are common during times of biological turnover and times when endemic biotas transform into cosmopolitan faunas.

This paper examines two waves of species invasions that occurred in the shallow marine realm during the Late Ordovician and Late Devonian periods as case studies in the long-term dynamics of species invasions.

\section{Case Study 1: Late Devonian Biodiversity Crisis}

The first case study of fossil-invasive species focuses on Late Devonian brachiopod and bivalve species of North America. The Late Devonian interval (approximately 385-370 million years ago) includes one of the five largest biodiversity crises in Earth's history, the Late Devonian (Frasnian-Fammenian) Biodiversity Crisis (McGhee 1996). During this time, the highly endemic Middle Devonian faunas were replaced by a cosmopolitan Late Devonian fauna due to pervasive species invasions in the shallow marine environments of Laurentia, the continent including present-day North America, Greenland, and part of Western Europe. This interval was further characterized by extensive faunal instability including increased extinction, decreased speciation, and ecosystem restructuring. The Late Devonian is often referred to as a "mass extinction" event. However, recent analyses have indicated that, although Frasnian extinction rates were slightly increased, extinction rates were not statistically elevated above the typical extinction rate throughout geologic time (Bambach et al. 2004; Stigall 2012a); therefore, the primary cause of biodiversity loss was a reduction in the formation of new species during this interval. Nevertheless, the biodiversity decline was so severe that the marine ecosystem suffered a fundamental reorganization (Droser et al. 2000), and the vast reef tracts of the Middle Devonian disappeared from Earth's oceans for almost 100 million years.

In order to examine the role that species invasions played in promoting the biodiversity crisis, Rode and Lieberman (2004) mapped the ranges of over 300 individual species of brachiopods and bivalves for each of 19 temporal intervals spanning the Middle to Late Devonian Periods. The geographic extent and position of species ranges were reconstructed using geographic information systems (GIS; Fig. 1). Based on the data of Rode and Lieberman (2004), species that survived the crisis interval had significantly larger geographic ranges than those that became extinct. Furthermore, species that exhibited at least one episode of invasion between tectonic basins during the Late Devonian were more likely to survive than species that remained in a single basin. The average geographic range size for species was tightly correlated with sea level in each temporal interval (based on the sea level curve of Johnson et al. (1985)), and most species invasions between basins occurred in pulses which coincided with rises in sea level that allowed marine water to breach otherwise emergent geographic barriers between basins (Fig. 2). When these results are summarized, they indicate that during the Late Devonian, geographic expansion and associated species invasions were facilitated by specific rises in relative sea level. Species that participated in invasion events were more likely to survive the crisis interval, while endemic species (those inhabiting a single area) were more likely to become extinct. The persistence of widely distributed invasive species and extinction of locally distributed species generated ecological turnover and produced a cosmopolitan fauna populated by widespread species that were ecological generalists. A similar outcome-loss of locally adapted, specialized species and expansion of broadly adapted invasive species - is one potential outcome of the modern biodiversity crisis. 

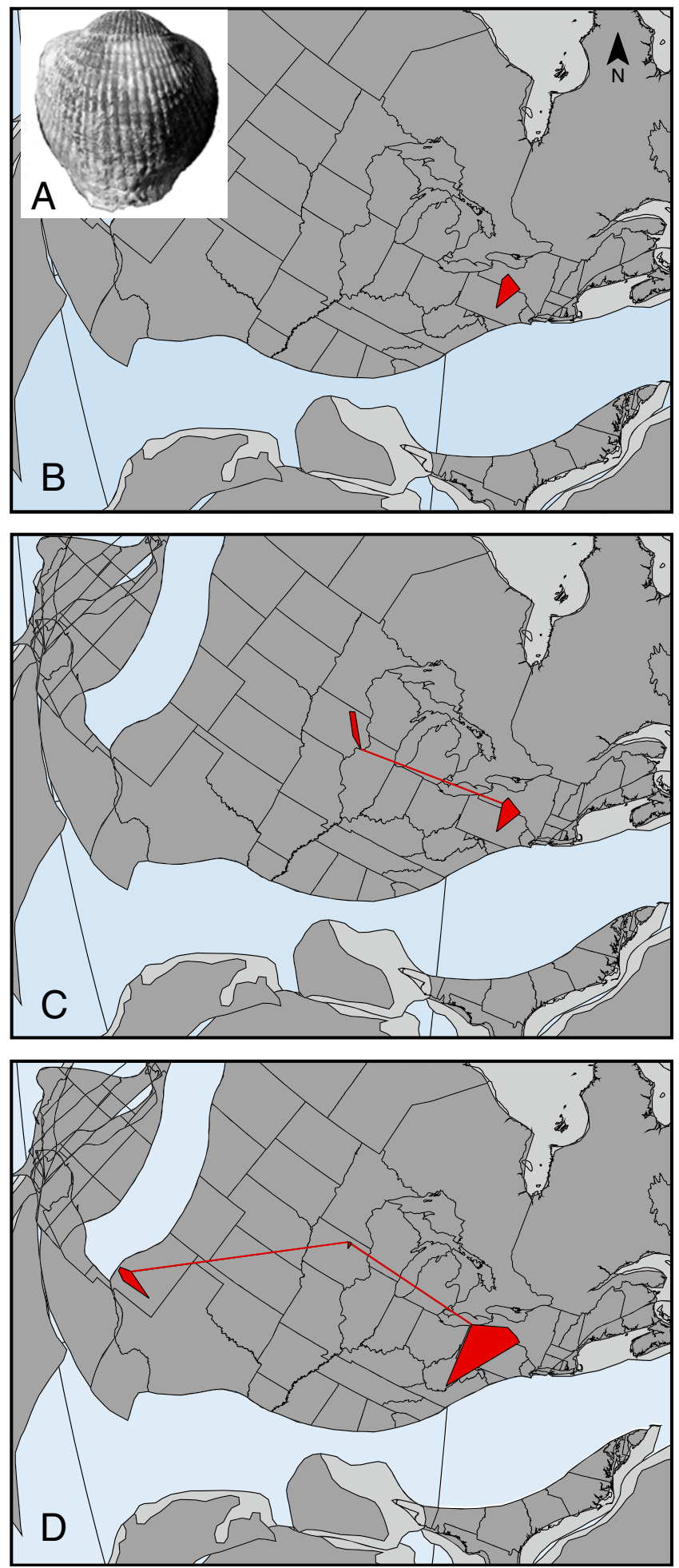

Fig. 1 Geographic range changes in a Late Devonian invasive species, Psuedatrypa devoniana (a), $0.75 \times$. b During the early Frasnian Stage, $P$. devoniana occupied its ancestral basin in the New York region; $\mathbf{c}$ this species invaded the Iowa basin during the middle Frasnian; $\mathbf{d}$ and subsequently invaded the New Mexico basin during the late Frasnian. The invasions correspond to the sea level rises indicated by the second and third arrow in Fig. 2. Modified from Rode and Lieberman (2004)
Since the Late Devonian crisis was due largely to speciation decline, understanding the extinction and persistence patterns of invasive vs. native species cannot explain the crisis fully; causes of speciation decline must be addressed explicitly. In order for speciation to occur, a group of individuals must become reproductively isolated from the remainder of their species (the ancestral species). The isolating factor is most often the separation of populations in geographic space (Mayr 1942). Geographic separation can occur either due to vicariance, where the ancestral species is passively divided into two or more isolated populations by the erection of a barrier, such as rising of a mountain range; or dispersal, where a subpopulation actively migrates away from the ancestral range, such as an interbasinal species invasion (Wiley and Mayden 1985). Under either scenario, the isolated population (incipient daughter species) subsequently develops morphological or behavioral differences via natural selection that prevent continued breeding with members of the ancestral species. Because the speciation process is explicitly tied to evolutionary events in geographic space, examining speciation patterns requires both species-level phylogenetic hypotheses and information about the geographic distribution of species.

Stigall (2010b) used species-level phylogenetic hypotheses of two brachiopod genera, a bivalve genus, and an order of crustaceans to examine Late Devonian speciation patterns. From this analysis, two clear patterns emerged. Firstly, both speciation and extinction rates were lower during the Late Devonian (Frasnian and Famennian Stages) Crisis than during the preceding Middle Devonian (Eifelian and Givetian Stages) in these taxa (Fig. 3). In fact, the rate at which new species formed declined to approximately zero during the Frasnian crisis interval. This result support those of genus-level analyses by McGhee (1996) and Bambach et al. (2004) and further reinforces the interpretation of the Late Devonian interval as a biodiversity crisis rather than a mass extinction event. Secondly, the primary mechanism for speciation reduction was the loss of speciation via vicariance (Stigall 2010b). During the Late Devonian, only $28 \%$ of speciation events were due to vicariance compared to 54-74\% during other intervals of geologic time (Stigall 2010b). Effectively, the primary mechanism of speciation in Earth history was shut down during the Late Devonian crisis interval. The speciation loss can be attributed to the high levels of species invasions present at this time (Stigall 2012a, b). Successful modern invasive species commonly exhibit broad levels of ecological tolerance, which allows them to exploit many types of environments (Davis 2009). This attribute also indicates that where invasive species are present, opportunities for new species to form would be reduced due to competition for resources. Incipient species, as discussed above, have relatively small population sizes, which means that these populations are more likely to become extinct than thrive and expand their population sizes when faced with fierce competition for resources. 


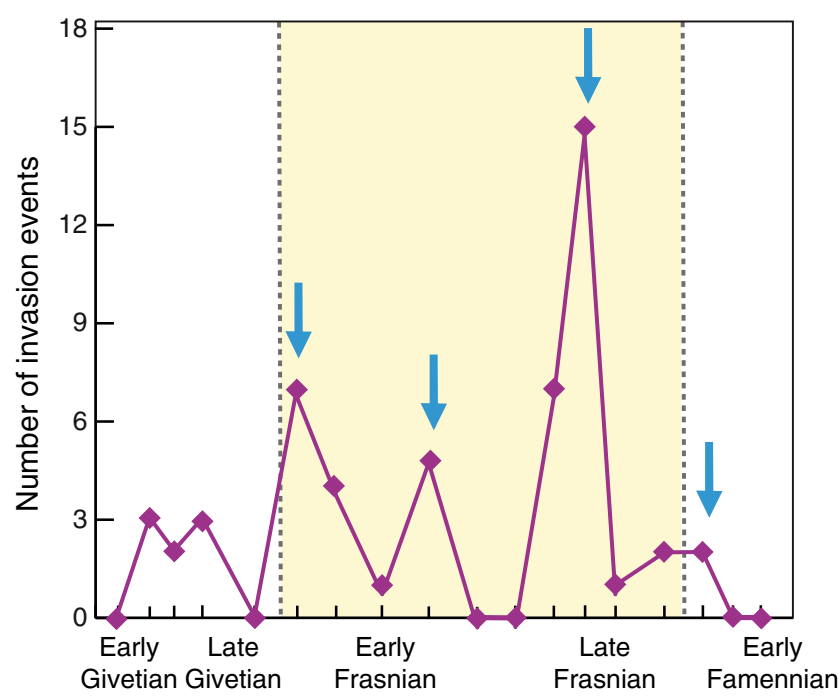

Fig. 2 Interbasinal invasion intensity during the Middle and Late Devonian. The spread of invasive species was facilitated by sea level rises, indicated by blue arrows. The Late Devonian Biodiversity Crisis interval is indicated in yellow. Modified from Stigall (2012a)

When the results of these Late Devonian analyses are combined, a clear picture begins to emerge of the impact of invasive species during this interval. The invaders themselves were highly successful at establishing themselves in new geographic areas following immigration events facilitated by rises in relative sea level. As a result of their widespread presence, speciation rates declined due to the lack of opportunities for speciation, particularly allopatric speciation. The few speciation events that occurred were due to dispersal, which is essentially an invasion event where the population that migrated later established a new species rather than maintained genetic flow with the ancestral species. Furthermore, the established species that were geographically restricted to a single depositional basin were more likely to become extinct during the crisis interval than species with an invasive history. This combination of features resulted in a post-crisis fauna characterized by geographic areas dominated by broadly adapted species, many with a history of invasion. Therefore, the potential long-term effects of modern invasive species include lack of new species forming, increased resistance of invaders to extinction, and ultimately faunal homogenization.

\section{Case Study 2: Late Ordovician Richmondian Invasion}

The second case study examines a basinal-scale invasion event during the Late Ordovician, the Richmondian Invasion. The Richmondian Invasion was an invasion of over 50 taxa into a shallow marine basin that was centered on present-day Cincinnati, Ohio and began at the boundary of the Maysvillian and Richmondian Stages ( $\sim 46$ million years ago; Meyer and Davis 2009). Invader species included taxa from shallow to

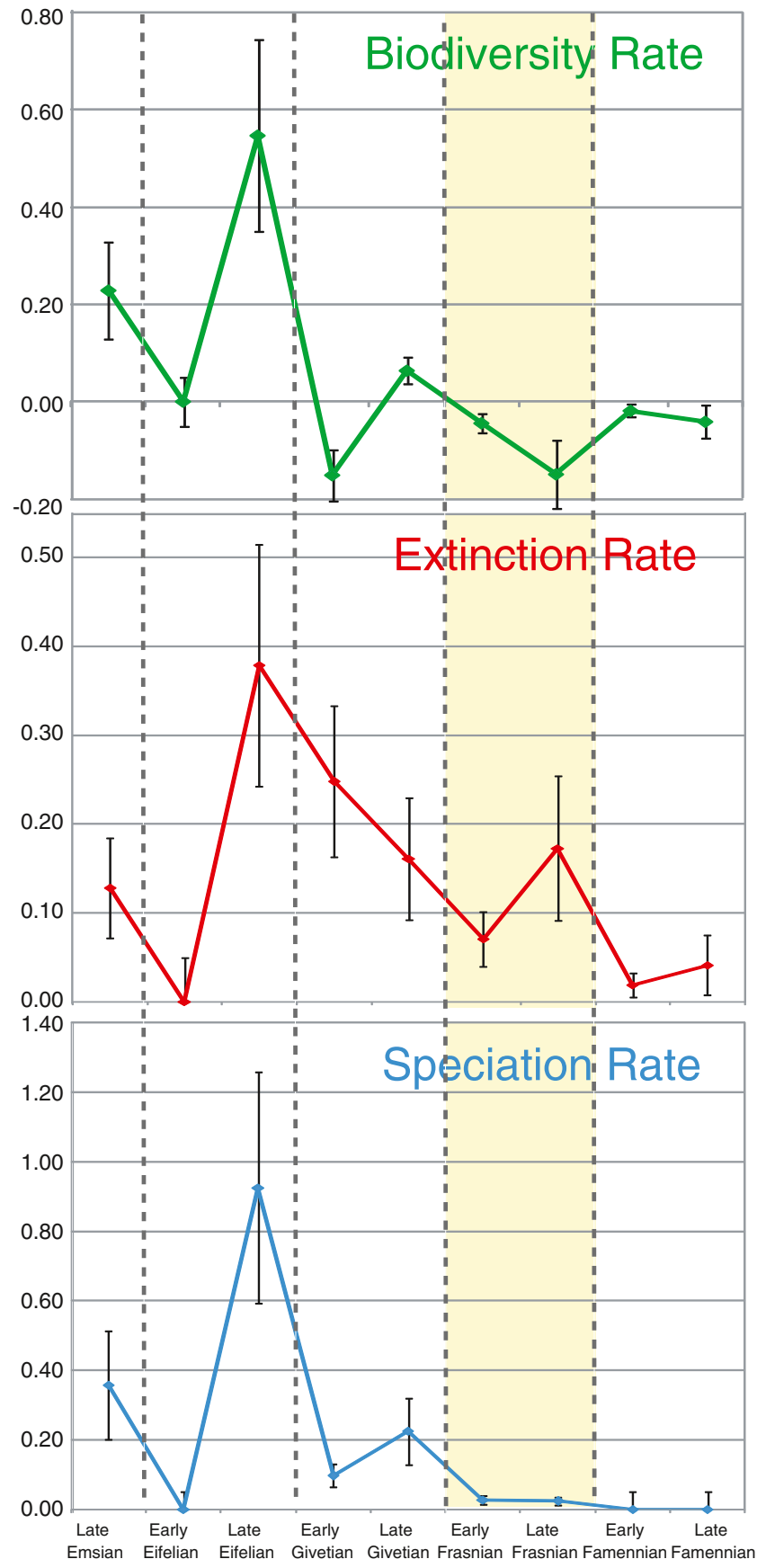

Fig. 3 Rate trends in biodiversity (change in total species extant during an interval), extinction (loss of species during an interval), and speciation (formation of new species) during the Middle and Late Devonian. The Late Devonian Biodiversity Crisis interval is indicated in yellow; the Middle/Late Devonian boundary coincides with the left margin of the yellow field. Modified from Stigall (2010b)

deep marine environments and all trophic levels. Notably, invader taxa included members of common Ordovician orders, such as rugose corals and rhynchonellid brachiopods, that were absent from the Cincinnati region prior to onset of the invasion. The invasion itself took place during several waves of introductions spread out over 500,000 years, likely 
due to shifts in oceanographic conditions (Patzkowsky and Holland 1996). The introduction of the Richmondian invaders resulted in the breakdown of the community structure that had persisted for the preceding five million years (Holland and Patzkowsky 2007). Following this invasion interval, a new stable ecosystem structure emerged in which invader species dominated the native species both in terms of biomass and species diversity.

To examine the biogeographic impact of the invasion, geographic ranges of articulate brachiopod species were reconstructed using GIS, as in the Devonian study by Stigall (2010a; Fig. 4). Species distribution data were collected for 45 species across six depositional sequences $(\mathrm{C} 1$ through $\mathrm{C} 6)$ to incorporate the interval prior to and following the Richmondian Invasion, which occurred in the $\mathrm{C} 4$ sequence. Each depositional sequence comprises strata deposited during a single cycle of rise and fall in relative sea level (Patzkowsky and Holland 1996). Individual depositional sequences, therefore, can be used as proxies for temporal intervals. Brachiopod species preserved in Cincinnatian strata during this interval were categorized into four groups: (1) species native to the Cincinnati region that became extinct by the end of the Maysvillian, (2) natives species that persisted into the Richmondian, (3) extrabasinal invaders that arrived during the Richmondian invasion, and (4) species that evolved in the Richmondian from Cincinnatian natives.

When geographic range sizes were compared by group, several patterns emerged (Stigall 2010a). Native species that persisted into the post-invasion interval had larger geographic ranges than species that did not (Stigall 2010a). This is consistent with the Devonian pattern in which generalist species preferentially survive intervals of biotic turnover compared to ecological specialists. In addition, the invasive species exhibited relatively large geographic ranges, indicative of ecological generalists (Stigall 2010a). Interestingly, the average range size of native species that survived into the Richmondian was larger than the average range size of the extrabasinal invaders throughout the invasion and the next million years. This suggests that although both survivors and invaders had relatively broad ecological tolerances, the only native species able to persist during the initial waves of biotic invasion were those with the broadest ecological niches. Conversely, new species that evolved in the Richmondian occupied small geographic ranges, suggesting radiation into empty ecological niches, including the specialist niches vacated by the extinction of the Maysvillian taxa (Stigall 2010a). Notably, only three speciation events were recorded during the early stages of the invasion in the $\mathrm{C} 4$ sequence; all other speciation events followed the stabilization of the post-invasion community structure. This is consistent with the Devonian analyses (e.g., Stigall 2012a, b) indicating decline in speciation rate and lack of vicariance during invasive regimes.

Clearly, a suite of native species persisted in the Cincinnati region following the Richmondian Invasion; however, analyzing the size of species' geographic ranges alone does not provide a complete analysis of how some native species were able to persist through the invasion interval. Geographic range sizes reconstructed solely from fossil occurrence data may underestimate the true geographic range of a species due to undersampling or lack of preservation of outcrop. One way to reduce this bias is to employ an analytical technique that incorporates both environmental and species occurrence data. Therefore, another way to examine invasion dynamics is to investigate whether or not species altered their ecological niches in response to invasion pressure. Range size and ecological niches are linked because the geographic range that any species occupies is a function of its ecological niche, the set of environmental tolerances and limits in multidimensional space that determine where a species in potentially able to maintain populations (Hutchinson 1957; Lomolino et al. 2006). Species that persisted through the invasion interval may have exhibited


Fig. 4 Changes in the geographic range size of Hebertella occidentalis (a, $0.6 \mathrm{x}$ ) during the Late Ordovician from the $\mathbf{b}$ pre-invasion ( $\mathrm{C} 1$ sequence), $\mathbf{c}$ invasion (C4 sequence), and d post-invasion (C5 sequence) intervals. This

native species successfully survives through the invasion due to its broad ecological tolerances that manifested as a large range size. The yellow region is the Late Ordovician outcrop belt. Modified from Stigall (2010a) 
one of two end-member responses to invasion pressure: niche conservatism or niche evolution (Stigall 2012b). Under niche conservatism, species maintain the parameters of their original ecological niche through time. These species cope with environmental change by tracking their preferred habitat laterally. In niche evolution, the parameters of a species' ecological niche are adapted via natural selection to better exploit the new environmental conditions.

The ecological niches of Cincinnatian brachiopods were modeled in a series of analyses (Dudei and Stigall 2010; Malizia and Stigall 2011; Stigall 2011; Walls and Stigall 2011) that examined the relative amount of niche stability in species before, during, and after the Richmondian Invasion. Species niches were modeled using a technique called ecological niche modeling for three time slices in each interval, generating a total of nine time slices for comparison (Fig. 5). Analyses indicated that species conserved the parameters of their ecological niche to a high degree during the pre-invasion interval (Malizia and Stigall 2011; Walls and Stigall 2011). Although no biotic invasion occurred during this interval, the Cincinnatian region and its biota did experience gradual environmental change due to gradual shallowing of the basin during the three time slices before the invasion (Walls and Stigall 2011). The overall biotic response to gradual change was niche conservation. Intervals of more rapid sea level rise exhibited slightly higher levels of niche evolution than during slower sea level change, but the overall pattern was still dominantly one of niche conservatism in the pre-invasion interval. However, the degree of niche conservatism declined significantly during the invasion interval (Dudei and Stigall 2010; Malizia and Stigall 2011). This indicates that the response of the biota to invasion pressure was to undergo adaptation and niche evolution. The interval of niche evolution continued throughout the invasion and at least the first million years of the post-invasion interval, as niche stability increased very slightly post-invasion but remained substantially below preinvasion stability levels (Malizia and Stigall 2011).

Thus, the amount of niche stability exhibited by Cincinnatian brachiopods is correlated with the speed of environmental change. During the gradual abiotic changes of the pre-invasion interval, species exhibited high levels of niche conservatism. Conversely, the rapid introduction of the Richmondian invaders resulted in niche evolution. As discussed above, the native species that persisted through the invasion interval were characterized by large geographic ranges, an indicator that these species could occupy a broad suite of environmental conditions (Stigall 2010a). Since these species entered the invasive regime with broad niches, they could undergo niche evolution in a way that focused their revised niche on a subset of their original niche rather than evolve new ecological tolerances (Stigall 2012b). This style of niche evolution would have provided a competitive advantage to the native species and allowed them to survive the ecosystem reorganization following the Richmondian Invasion. Interestingly, the invasive species exhibited similar levels of niche evolution to the native species in the postinvasion interval, which suggest a similar dynamic operated with these generalist species as well.

\section{Summary and Conclusions}

The results of the Late Devonian and Ordovician invasion analyses provide complementary insights into the long-term impacts of invasive species on native ecosystems. During both intervals, invasive species were characterized by broad ecological tolerances, broad geographic ranges, and higher-thanaverage survival potential through the crisis interval. Among the native species, narrowly adapted ecological specialists were more likely to become extinct, while broadly adapted generalist species persisted through the invasion interval by modifying aspects of their ecological niche through niche evolution. This suggests that in order to avoid extinction, native species must retain broad ecological tolerances and, most importantly, the ability to evolve and adapt in the face of increased competition due to species invasions. Furthermore, the presence of invasive species reduced speciation rate during the invasion interval of both time periods. This occurred primarily by reducing geographic isolation. High levels of dispersal, associated with interbasinal invasions, reduced opportunities for allopatric speciation. The culmination of these long-term impacts resulted in post-invasion ecosystems that fundamentally differ from the pre-invasion biota. The resulting faunas were dominated by relatively few broadly adapted generalist species, most of which were invasive taxa. This promoted biotic homogenization between regions, extinction of local endemic species, and blocked new species from forming.

We might expect the same long-term effects of invasive species to manifest themselves in the current biodiversity crisis. Clearly, the loss of endemic species and biotic homogenization between regions is already occurring (Williamson 1996). Based on the Devonian and Ordovician analogs, we should also expect that speciation levels will decline. This aspect is particularly poignant because the modern biodiversity crisis adds high rates of extinction due to habitat destruction (issues not particularly significant during the Devonian or Ordovician) to the problems associated with invasive species. In fact, extinction levels today exceed those present during any of the mass extinctions preserved in the fossil record (Lawton and May 1995). The current combination of high extinction, reduced speciation, and biotic homogenization 
Fig. 5 Ecological niche model projection maps. Predicted range of Rafinesquina alternata (e, $0.5 \times)$ illustrating high niche stability during the pre-invasion interval, a predicted range for the C3-2 time slice based on C3-2 niche model, $\mathbf{b}$ predicted range for the C3-3 time slice based on the C3-2 niche model, c predicted range during the C3-3 time slice based on the C3-3 niche model, $\mathbf{d}$ calculated overlap between $\mathbf{b}$ and $\mathbf{c}$, a measure of niche stability. If a species occupied exactly the same niche in two time slices, these range maps would completely overlap. The $88 \%$ overlap indicates strong niche conservatism. Predicted range of Lepidocyclas perlamellosus (j, 0.75×) illustrating low niche stability during the postinvasion interval, $\mathbf{g}$ predicted range for the $\mathrm{C} 5-2$ time slice based on C5-2 niche model, $\mathbf{g}$ predicted range for the $\mathrm{C} 5-3$ time slice based on the $\mathrm{C} 5-2$ niche model, $\mathbf{h}$ predicted range during the $\mathrm{C} 5-3$ time slice based on the C5-3 niche model, i calculated overlap between $\mathbf{g}$ and $\mathbf{h}$. The $54 \%$ overlap indicates substantial niche evolution. For $\mathbf{a}-\mathbf{c}$ and $\mathbf{f}-\mathbf{h}$, light colors indicate low predicted probability of occurrence while dark colors indicate high predicted probability of occurrence. In $\mathbf{d}$ and $\mathbf{i}$, light colors indicate low agreement between original and forward model projections while dark colors indicate high agreement. Modified from Malizia and Stigall (2010)
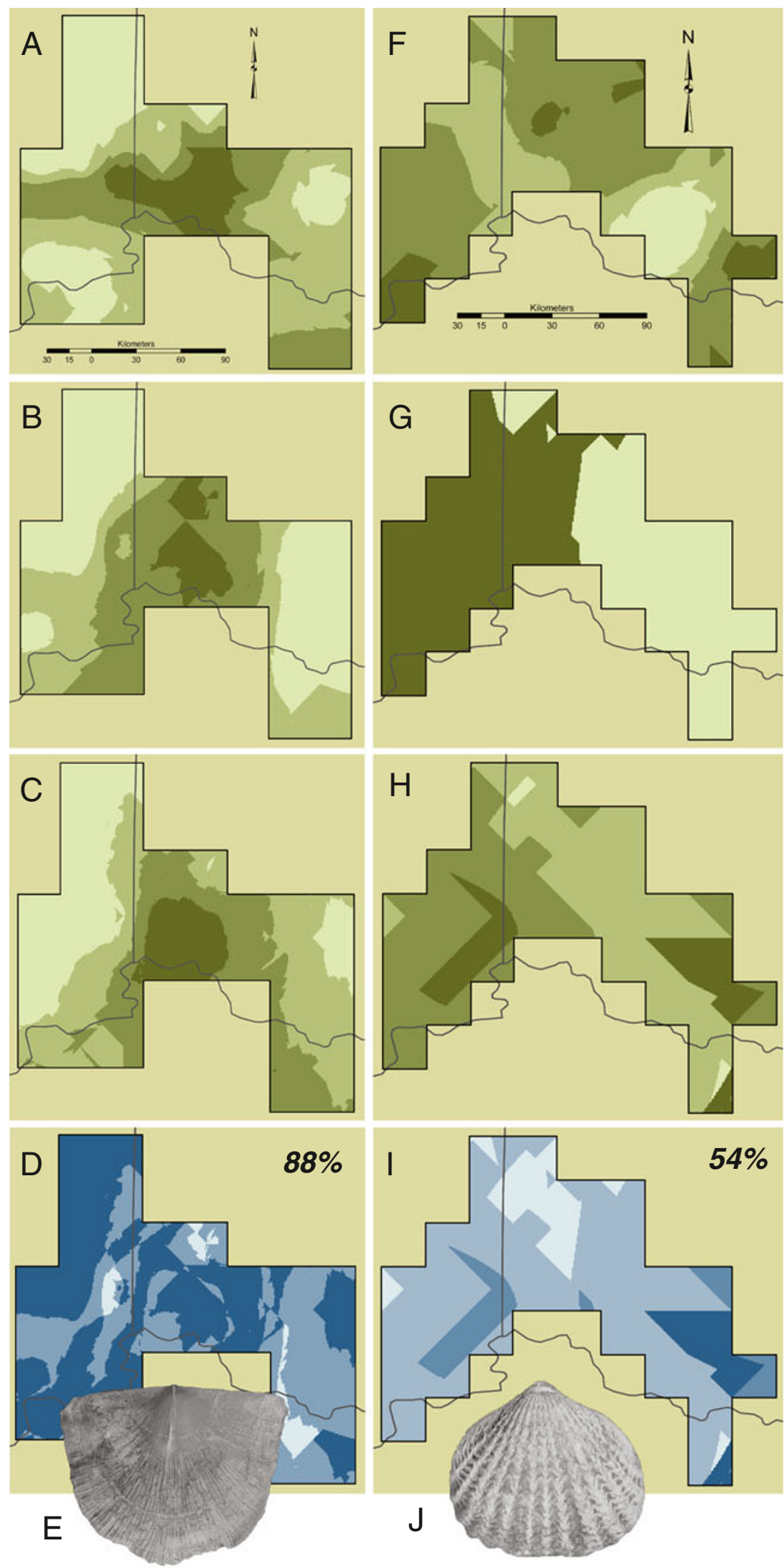
could produce a very low diversity biota on our planet. Conservation efforts, including habitat protection, federal regulation of species importation, and removal of already established invasive species, are critical to the protection of the biodiversity on our planet today. Many efforts of this type are already underway, but expansion of the programs and involvement of volunteers (like you) are critical to their success.

Acknowledgments Thanks to Jonathan Hendricks and an anonymous reviewers for constructive reviews and to Bruce Lieberman for the invitation to submit this research to this edited volume. This research was supported by NSF EAR-0922067 and a grant from the donors of the American Chemical Society's Petroleum Research Fund.

\section{References}

Bambach RK, Knoll AJ, Wang SC. Origination, extinction, and mass depletions of marine diversity. Paleobiology. 2004;30:522-42.

Blaustein RJ. Kudzu's invasion into Southern United states life and culture. The great reshuffling: human dimensions of invasive species. Cambridge, UK: The World Conservation Union; 2001. p. 55-62.

Davis MA. Biotic globalization: does competition from introduced species threaten biodiversity? Bioscience. 2003;53:481-9.

Davis MA. Invasion biology. Oxford: Oxford University Press; 2009. p. 288.

Droser ML, Bottjer DJ, Sheehan PM, McGhee Jr GR. Decoupling the taxonomic and ecologic severity of Phanerozoic marine mass extinctions. Geology. 2000;28:675-8.

Dudei NL, Stigall AL. Using ecological niche modeling to assess biogeographic and niche response of brachiopod species to the Richmondian Invasion (Late Ordovician) in the Cincinnati Arch. Palaeogeogr Palaeoclimatol Palaeoecol. 2010;296:28-47.

Enserink M. Biological invaders sweep in. Science. 1999;285:1834-6.

Fritts TH, Rodda GH. The role of introduced species in the degradation of an island ecosystem: a case history of Guam. Annu Rev Ecol Syst. 1998;29:113-40.

Holland SM, Patzkowsky ME. Gradient ecology of a biotic invasion: biofacies of the type Cincinnatian Series (Upper Ordovician), Cincinnati, Ohio Region, USA. Palaios. 2007;22:392-407.

Hutchinson GE. Concluding remarks. Cold Spring Harbor Symposium on Quaternary Biology. 1957;22:415-27.

Johnson JG, Klaper G, Sandberg CA. Devonian eustastic fluctuations in Euramerica. Geol Soc Am Bull. 1985;96:567-87.

Lawton JH, May RM. Extinction rates. Oxford, UK: Oxford University Press; 1995. 248 p.

Lockwood J, Hoopes M, Marchetti M. Invasion ecology. Singapore: Blackwell; 2007. p. 312.
Lomolino MV, Riddle BR, Brown JH. Biogeography. 3rd ed. Sunderland, Massachusetts: Sinauer; 2006.

Malizia RW, Stigall AL. Analyzing niche stability in Late Ordovician articulated brachiopods during the Richmondian Invasion. Geological Society of America Abstracts with Programs. 2010;42(5):258.

Malizia RW, Stigall AL. Niche stability in Late Ordovician articulated brachiopod species before, during, and after the Richmondian Invasion. Palaeogeogr Palaeoclimatol Palaeoecol. 2011; 311:154-70.

Mayr E. Systematics and the origin of species. New York: Columbia Univ. Press; 1942. p. 367.

McGhee Jr GR. The Late Devonian mass extinction; the Frasnian/ Famennian crisis. New York: Columbia Univ. Press; 1996. p. 303.

Meyer DL, Davis RA. A sea without fish: life in the Ordovician sea of the Cincinnati region. Bloomington: Indiana University Press; 2009. p. 346.

Patzkowsky ME, Holland SM. Extinction, invasion, and sequence stratigraphy; patterns of faunal change in the Middle and Upper Ordovician of the Eastern United States. Paleozoic Sequence Stratigraphy: views from the North American Craton. Boulder, Colorado: Geological Society of America; 1996. p. 131-42.

Pimentel D, Zuniga R, Morrison D. Update on the envrionmental and economic costs associated with alien-invasive species in the United States. Ecol Econ. 2005;52:273-88.

Rode AL, Lieberman BS. Using GIS to unlock the interactions between biogeography, environment, and evolution in Middle and Late Devonian brachiopods and bivalves. Palaeogeography, Palaeoclimatology, Palaeogeography. 2004;211:345-59.

Stigall AL (2010a) Using GIS to assess the biogeographic impact of species invasions on native brachiopods during the Richmondian Invasion in the Type Cincinnatian (Late Ordovician, Cincinnati region). Palaeontologia Electronica 13: 5A http://palaeo-electronica. org/2010 1/207/index.html

Stigall AL. Invasive species and biodiversity crises: testing the link in the Late Devonian. PLoS One. 2010b;5(12):e15584. doi:10.1371/ journal.pone. 0015584 .

Stigall AL. Application of niche modeling to analyze biogeographic patterns in Palaeozoic brachiopods: evaluating niche stability in deep time. Memoirs of the Association of Australasian Palaeontologists. 2011;41:229-55.

Stigall AL. Speciation collapse and invasive species dynamics during the Late Devonian "Mass Extinction”. GSA Today. 2012a;22(1):4-9.

Stigall AL. Using ecological niche modeling to evaluate niche stability in deep time. J Biogeogr. 2012b. doi:10.1111/j.13652699.2011.02651.x.

Walls BJ, Stigall AL. Analyzing niche stability and biogeography of Late Ordovician brachiopod species using ecological niche modeling. Palaeogeogr Palaeoclimatol Palaeoecol. 2011;299:15-29.

Wiley EO, Mayden RL. Species and speciation in phylogenetic systematics, with examples from North American fish fauna. Ann MO Bot Gard. 1985;72:596-635.

Williamson M. Biological invasions. London: Chapman and Hall; 1996. p. 244. 